\title{
THE RELATIONSHIP BETWEEN TIME OF CLUSTER DIFFERENTIATION AND PHENOLOGICAL STAGES WITH SPECIAL FOCUS ON ASSESSMENT OF BUD FERTILITY AND BUD NECROSIS AS MEANS FOR IMPROVING VINE PRODUCTIVITY OF SOME GRAPE CULTIVARS \\ El-Mogy, M. M.; M. A. Abd El-Wahab and Gehan H. Sabry \\ Viticulture Dept., Hort. Res. Instit., Agric. Res. Center, Giza, Egypt
}

\begin{abstract}
This study was carried out for three successive seasons (2006, 2007 and 2008) in a private vineyard located at El-Khatatba, Menoufiya governorate; to determinate the relationship between time of cluster differentiation and phenological stages of vine annual growth cycle with special focus on assessment of bud fertility and bud necrosis sensitivity of eight grape varieties; Flame Seedless, Superior, Beauty Seedless, Black Monukka, Rich Baba, Red Globe, Black Rose, and Ribier. The chosen vines were 10 year-old, grown in a sandy soil, spaced at $2 \times 3$ meters apart and irrigated by the drip irrigation system, cane-pruned and trellised by the Spanish Parron shape system.

The results showed that the time of cluster differentiation is closely correlated closely with phenological stages. However, cluster differentiation occurs just after ful bloom time and continues almost until fruit harvest for all varieties in the three seasons of this study. It was noticed that, percentage of dissected bud fertility along 'Flame Seedless' shoots through the different phenological dates recorded the greatest values compared to the other varieties, followed by Beauty Seedless and Red Globe grape varieties. On the other hand, Black Monukka and Superior grape varieties gave the lowest percentage of dissected bud fertility along shoots through phenological dates in the three seasons of the study.

With respect to percentage of bud necrosis, data compiled from bud dissection analysis showed a significant difference in the levels of bud necrosis (BN) among varieties under investigation in the three seasons. In this respect, Flame Seedless and Black Monukka grape varieties had the highest incidence of BN followed by Superior, Beauty Seedless, Red Globe and Black Rose which were found to be intermediate in this respect. On the other hand, Ribier and Rich Baba grape varieties were the lowest during all seasons of this study.
\end{abstract}

\section{INTRODUCTION}

As one of the premises for crop yield, grapevine bud fruitfulness has been the focus of many studies, reviewed by several authors (Buttrose 1974, Srinivasan and Mullins 1981 and May 2000). Since productivity of cultivars may vary widely from year to year.

The low and erratic bud fruitfulness of table grape varieties is the single most significant problem. The poor bud fruitfulness and low cropping levels experienced during the few recent years have substantially reduced the economic feasibility of table grape production.

To improve bud fruitfulness, table grape growers should focus their efforts on this critical period and employ at the appropriate time management strategies (fertilizer, irrigation,...etc) as to be more effective in improving fruitfulness when cluster differentiation occurs through the phenological stages of the grapevine. 
Vitis vinifera grapevines are phenologically distinct crop with the most important developmental stages being débourrement (budburst), floraison (flowering), veraison (color change and maturation nascent), and harvest (grape maturity). The time between these phenological stages varies greatly with grapevine variety, climate, and geographic location (Jones and Davis 2000).

Time of cluster differentiation of grapevine inflorescence primordia that make up the next year's crop in the compound bud begins around bloom time and continues almost until it is completed between veraison and harvest (May and Antcliff 1963; Swanepoel and Archer 1988 and Williams 2000). Therefore, the number of flower primordia per vine (and thus the potential yield) is determined during the previous year.

Bud necrosis (BN) of grapevines is a physiological disorder of the compound buds of grapevines resulting in the death of the primary bud (Bindra and Chohan, 1975; Hopping, 1977; Bains et al., 1981; Lavee et al., 1981; Naito et al., 1986; Lavee, 1987; Morrison and lodi, 1990; Perez and Kliewer, 1990; Dry and Coombe, 1994; Wolf and Warren, 1995). The disorder usually affects the primary buds, but occasionally the secondary buds are also affected. Primary buds produce the fruiting shoots for the following season. When primary buds abort, the secondary buds undergo further development and produce the following year's fruiting shoots. Shoots that develop from secondary buds typically have smaller and fewer fruit clusters. Therefore, the crop yield of secondary shoots is lower than that of primary shoots.

Despite the widespread occurrence of $\mathrm{BN}$, the principal cause is uncertain. High rates of shoot growth and large cane diameter (Lavee et al., 1981; Lavee, 1987; Dry and Coombe, 1994 and Wolf and Warren, 1995), shading of buds (Perez and Kliewer, 1990 and Wolf and Warren, 1995), excessive irrigation (Bindra and Chohan, 1975; Perez, 1991), low carbohydrate levels in bud tissues (Naito et al., 1987), high gibberellinlike activity in buds (Ziv et al., 1981 and Lavee, 1987) and mite infestation and fungal diseases (Rawnsley et al., 2002) have all been associated with bud necrosis.

The incidence of BN appears to be cultivar-specific. Researches on BN and fruitfulness have been widely conducted on table grapes, such as Thompson seedless (Sultana) and Queen of Vineyard (Lavee et al., 1981).

The time that BN develops is dependent on cultivar. It was reported that BN commences soon after flowering (Lavee et al., 1981) and may develop up to 10 weeks after full bloom (Morrison and lodi, 1990). Vineyards with BN often display vigorous shoot growth as a consequence of the unfruitful secondary shoots compensating for the loss of the primary bud. BN may also lead to development of two secondary shoots from the same node (Dry and Coombe, 1994), yet overall bunch number is reduced. Poor fruitfulness may indicate high levels of $\mathrm{BN}$ in the vineyard.

This survey cleared that grape growers should be aware of BN incidence as a potential vineyard problem, and as such, grape-growers have to change their management strategies to compensate for high levels of BN.

The objective of this study is to improve vineyard productivity through 
determination of the relationship between time of cluster differentiation and phenological stages of vine annual growth cycle with special focus on assessment of bud fertility and bud necrosis sensitivity of eight grape varieties; Flame Seedless, Superior, Beauty Seedless, Black Monukka, Rich Baba, Red Globe, Black Rose, and Ribier.

\section{MATERIALS AND METHODS}

This study was carried out in a private vineyard located at El-Khatatba, Menoufiya governorate; to improve vineyard productivity through the determination of the relationship between time of cluster differentiation and phenological stages with special focus on the assessment of bud fertility and bud necrosis sensitivly of eight grape varieties; Flame Seedless, Superior, Beauty Seedless, Black Monukka, Rich Baba, Red Globe, Black Rose, and Ribier. The study extended for three successive seasons (2006, 2007 and 2008). The vines were 10-year-old, grown in a sandy soil, spaced at $2 \times 3$ meters apart, irrigated by the drip irrigation system, cane-pruned and trellised by the Spanish Parron shape system. The vines were pruned during the second week of January for the three seasons of the study so as to maintain a load of (10 canes X 12 buds/cane). Four replicates for each cultivar were taken where each replicate consisted of nine vines and subjected to the same cultural practices usually carried out for these cultivars.

The following parameters were measured to evaluate the tested varieties:-

\section{1) Phenological data}

The considered aspects: the $1^{\text {st }}$, date of bud burst, i.e. opening of $50 \%$ buds; the $2^{\text {nd }}$, date of full bloom: the vines were considered to reach full bloom when the calyptra had fallen from $70-80 \%$ of the flowers; the $3^{\text {rd }}$, date of fruit set: when the fertilized flower begins to be a berry; the $4^{\text {th }}$, date of veraison: when the berries start to soften as they build up sugars and acids begin to fall or the berries reach to the onset of colour stage; the $5^{\text {th }}$, date of harvesting: it takes place when the berries attain full colour stage and the TSS reach $16-17 \%$ according to Tourky et al., (1995).

a) Time of phenological dates (budburst, full bloom, fruit set, veraison and ripening) was estimated periodically.

b) Number of days for phenological dates was calculated periodically by calendar year (Julian day).

\section{2) Time of cluster differentiation}

Samples of primary bud along a 12-node current season shoots of at least 15 individual shoots for the eight grape varieties were collected periodically through dates of full bloom, fruit set, veraison, ripening and winter pruning during the seasons of the study. Samples were examined microscopically for the presence of floral primordia and calculated periodically by calendar year (Julian day). The method was conducted through the handling faster anatomy described by Ambika and pondey, (1969).

3) Bud fertility and bud necrosis

Number of predicted bud fertility and bud necrosis were estimated at 
winter pruning time on dormant buds borne on 10 canes each of 12 buds for the eight grape varieties by microscope binocular. The method was conducted through the handling faster anatomy described by Ambika and pondey, (1969).

a) Percentage of predicted bud fertility at different bud positions lengthwise the cane: This was calculated by dividing the total number of dissected fertile buds per vine by the total number of buds per vine at each bud position.

b) Percentage of actual fruiting shoots in spring after bud burst at different bud positions lengthwise the cane: This was calculated by dividing the total number of fruit shoots per vine by the total number of buds per vine.

c) Percentage of bud necrosis: It was calculated by dividing number of necrotic buds per vine by the total number of buds per vine.

- Statistical analysis:

The completely randomized design was carried out for this experiment. The statistical analysis of the present data was made according to Snedecor and Chocran (1972). Averages were compared using the new L.S.D. values at $5 \%$ level. Percentages were transformed by a certain equation prior to the statistical analysis.

\section{RESULTS AND DISCUSSION}

\section{1) Phenological data}

Data in (Table, 1 and Figure, 1) revealed that Flame Seedless and Superior grape were the earliest varieties with regard to the phenological dates (budburst, full bloom, fruit set, veraison and grape maturity) compared to the other varieties whereas, Red Globe, Black Rose, and Ribier grape varieties were the latest in this respect. On the other hand, Beauty Seedless, Black Monukka and Rich Baba Ribier grape varieties were intermediate in the three seasons.

Data concerning number of days by calendar year (Julian day) for phenological dates as shown in (Table, 2 and Figure, 2) revealed a remarkable variation among varieties under investigation. In this respect, Flame Seedless and Superior grape varieties had the lowest number of days as compared to the other varieties followed by Beauty Seedless, Black Monukka and Rich Baba grape varieties were found to be intermediate in this respect. On the other hand, Red Globe, Black Rose and Ribier grape varieties had the highest number of days in all seasons of the study.

The obtained results in this connection are in harmony with those mentioned by Abd-El-Fattah and Kasstor (1993a) on Beauty Seedless and Black Monukka grape varieties; Abd-El-Fattah and Kasstor (1993b) on Black Rose and Ribier grape varieties; Aisha et al., (1998) on Black Monukka and Ribier grape varieties; Marwad (2002a) on Black Rose and Ribier grape varieties and Marwad (2002b) on Beauty Seedless and Black Monukka grape varieties. 
J. Agric. Sci. Mansoura Univ., 34 (5), May, 2009 $\mathrm{T} 1$ 
El-Mogy, M. M. et al.

F1 
J. Agric. Sci. Mansoura Univ., 34 (5), May, 2009 T2 
El-Mogy, M. M. et al.

F2 


\section{2) Time of cluster differentiation}

Time of cluster differentiation within the compound bud in all studied varieties begins just after full bloom time and continues almost until fruit harvest along the 12-node shoot (Table, 3 and Figure, 3).

It is interesting to note that potential bud fruitfulness (dissected bud fertility \%) showed a remarkable variation among varieties under investigation. In this respect, percentage of dissected bud fertility along 'Flame Seedless' shoots through phenological dates (full bloom, fruit set, veraison, harvest grape maturity and winter pruning) recorded the greatest values in comparison with the other varieties. The percentage was $(16.7 \%)$ after 115 days of year at fruit set, $(55.7 \%)$ after 133 days of year at veraison, (76.3\%) after 163 days of year at fruit ripening and (77.9\%) after 325 days of year at winter pruning, followed by Beauty Seedless and Red Globe grape varieties. On the other hand, Black Monukka and Superior grape varieties recorded the lowest percentage of dissected bud fertility along shoots through the phenological dates in the three seasons of the investigation.

It can be shown from the aforementioned data that definite relationships between phenological dates and time of cluster differentiation could be identified. Correlations illustrated in Figure (3) indicated that phenological dates are closely related to bud fruitfulness for the grape varieties under investigation.

These results are in accordance with those obtained by (May and Antcliff 1963; Swanepoel and Archer 1988 and Williams 2000) who found that time of cluster differentiation of grapevine inflorescence primordia that make up the next year's crop in the compound bud begins around bloom time and continues almost until it is completed between veraison and harvest.

\section{3) Prediction of bud fertility, actual fruiting shoots and bud necrosis}

It is important to determine percentage of predicted bud fertility for each bud position as to help for the choice of the suitable pruning system for each cultivar.

With respect to percentage of predicted bud fertility at different bud positions lengthwise the cane, data in (Figure, 4) show that the first basal bud had the least percentage of bud fertility as compared to the subsequent buds. A remarkable increase attaining its maximum percentage occurred from the $2^{\text {nd }}$ to the $4^{\text {th }}$ bud for Flame Seedless grape variety, from the $3^{\text {rd }}$ to the $5^{\text {th }}$ bud for Beauty Seedless, Rich Baba, Red Globe, Black Rose and Ribier grape varieties. Black Monukka and Superior grape varieties recorded the highest percentage of bud fertility from the $5^{\text {th }}$ to the $8^{\text {th }}$ bud in three seasons.

As regards percentage of actual fruiting shoots lengthwise the cane, the results illustrated in (Figure, 4) revealed that, it exhibited a trend similar to that of the percentage of predicted bud fertility lengthwise the cane for all grape varieties under investigation. The similarity of the trend of both predicted and actual fruiting suggests that the forecasting through the examination of bud fertility during winter may be a reliable guide for winterpruning and fruiting of the eight grape varieties in the following season.

The percentage of predicted bud fertility detected at dormancy period was approximately the same for the actual fruiting shoots at spring. 
EI-Mogy, M. M. et al.

T3

4818 
J. Agric. Sci. Mansoura Univ., 34 (5), May, 2009

F3

4819 
EI-Mogy, M. M. et al.

F4 
However the percentage of predicted bud fertility was higher as compared to that of actual fruiting shoots for all grape varieties under investigation in the three seasons. This difference may be ascribed to the environmental factors and agricultural practices.

From the previously mentioned results, it can be recommended to prune Flame Seedless, Beauty Seedless, Rich Baba, Red Globe, Black Rose and Ribier grape varieties according to the spur pruning system while Black Monukka and Superior can be pruned according to the cane pruning system.

These results agree with the findings of Bessins (1965), Licul (1969), Monastra (1971), Abd El-Kawi and El-Yami (1992) and Aisha et al., (1998) who found that the fruitfulness of buds increased from the basal sector to the distal bud position on the canes.

With respect to percentage of bud necrosis, data compiled from bud dissection analysis (Table, 4 and Figure, 5 \& 6) showed significant differences in the levels of bud necrosis (BN) among the varieties under investigation in the three seasons. In this respect, Flame Seedless and Black Monukka grape varieties had the highest incidence of BN compared to other varieties followed by Superior, Beauty Seedless, Red Globe and Black Rose which were found to be intermediate in this respect. On the other hand, Ribier and Rich Baba grape varieties were the lowest in all seasons of the study.

Despite the widespread occurrence of $\mathrm{BN}$, the principal cause is uncertain. High rates of shoot growth and large cane diameter (Lavee et al., 1981; Lavee, 1987; Dry and Coombe, 1994 and Wolf and Warren, 1995), shading of buds (Perez and Kliewer, 1990 and Wolf and Warren, 1995), excessive irrigation (Bindra and Chohan, 1975; Perez, 1991), low carbohydrate levels in bud tissues (Naito et al., 1987), high gibberellinlike activity in buds (Ziv et al., 1981 and Lavee, 1987) and mite infestation and fungal diseases (Rawnsley et al., 2002) have all been associated with bud necrosis.

The incidence of BN appears to be cultivar-specific. Researches on BN and fruitfulness have been widely conducted on table grapes, such as Thompson seedless (Sultana) and Queen of Vineyard (Lavee et al., 1981).

The results highlighted that $\mathrm{BN}$ is a problem in most grape varieties under study, particularly in Flame Seedless, Black Monukka, Superior, Beauty Seedless, Red Globe and Black Rose grape varieties. It can be concluded from the results obtained that in this investigation grapegrowers should be aware of BN incidence as a potential vineyard problem, and as such, grape-growers have to change their management strategies to compensate for high levels of BN.

The correlation between high BN levels and low fruitfulness is important in terms of crop forecasting to meet target yields (Lavee et al., 1981; Dry and Coombe, 1994). It has been suggested that factors leading to a reduced number of inflorescences also contribute to the process leading to $\mathrm{BN}$ incidence (Lavee et al., 1981). The high degree of variability found between different vineyards indicate that it would be difficult to estimate $B N$ regionally and may be more reliant on other factors. 
El-Mogy, M. M. et al.

T4

4822 
J. Agric. Sci. Mansoura Univ., 34 (5), May, 2009 F5 
EI-Mogy, M. M. et al.

F6 
This implies that each vineyard would need to be managed on a case-bycase basis and factors such as seasonal changes and block variability would need to be considered to accurately estimate BN levels.

The following are the possible recommendations which could be given according to the obtained results:-

- Horticultural practices should be applied at the appropriate time and with the required accuracy so as to prepare the vine for the proper floral bud differentiation of cluster primordia especially after full bloom time and continues almost until fruit harvest.

- It is required to raise vine bud load during winter pruning in accordance with percentage of bud necrosis detected through the microscopically examination of buds.

\section{REFERENCES}

Abd El-Fattah, S.E. and Kasstor, S. (1993a): Evaluation of some introduced grapevine cultivars. (A) Seedless cultivars. Minia. J. Agric. Research and Development, 30, 477-491.

Abd El-Fattah, S.E. and Kasstor, S. (1993b): Evaluation of some introduced grapevine cultivars. (B) Seeded cultivars. Minia. J. Agric. Research and Development, 31, 493-505.

Abd El-Kawi, A. and El-Yami, S.A. (1992): Bud behaviour of four grape varieties in Taif Region. S.A.J. Agric. Sci. Mansoura. Univ. 17 (7): 2451-2456.

Aisha S.A. Gaser, El-Mogy, M.M. and Omar, A.H. (1998): Comparative studies on description and evaluation of five new table grape cultivars under Egyptian conditions: Annals of Agric. Sci., Vol 36 (4) 2473-2486.

Ambika Prasad and Pandey, S. D. (1969): A simple and quick method to determine fruitfulness of dormant duds in grape. The Indian J. of Hort. Vol. (26) No. 3 and 4.

Bains, K. S.; Bindra, A. S. and Bal, J. S. (1981): Seasonal changes in carbohydrate and mineral composition of vigorous and devitalized Anab-e-Shahi grapevines in relation to unfruitfulness. Vitis 20: 311-319.

Bessins, R. (1965): Recherché sur la fertilite' et les correlations de croissance entre bourgeons. These Sci. Nat. Univ. Dijon. France.

Bindra, A. S. and Chohan, J. S. (1975): Flower-bud killing in Anab-e-Shahi grapes. Indian J. Mycol. Plant Pathol. 5: 63-68.

Buttrose, M.S. (1974): Fruitfulness in grapevines: effects of water stress. Vitis 12: 299-305.

Dry, P.R. and Coombe, B.G. (1994): Primary bud-axis necrosis of grapevine. I. Natural incidence and correlation with vigour. Vitis 33: 225-230.

Hopping, M. E. (1977): Effect of light intensity during cane development on subsequent bud break and yield of 'Palomino' grapevines. N. Z. J. Exper. Agricult. 5: 287-290.

Jones, G. V. and Davis, R. E. (2000): Climate Influences on Grapevine Phenology, Grape Composition, and Wine Production and Quality for Bordeaux, France. Am. J. Enol. Vitic., 51( 3): 249-261. 
Lavee, S. (1987): Necrosis in grapevine buds (Vitis vinifera cv. Queen of Vineyard). III. endogenous gibberellin levels in leaves and buds. Vitis 26: 225-230.

Lavee, S., Ziv, M. M. and Bernstein, Z. (1981): Necrosis in grapevine buds (Vitis vinifera cv. Queen of Vineyard). I. Relation to vegetative vigor. Vitis 20: 8-14.

Licul, R. (1969): Determination of bud Fruitfulness in different wine varieties. Poljopr Zananst Somatra, 25 (5): 1-24 (Hort. Abst. 41:8690).

Marwad, I.A. (2002a): Comparative studies of five seedless grape cultivars under conditions of Qalubia governorate, Egypt. J. Appl. Sci., 17 (1) 307-326.

Marwad, I.A. (2002b): Comparative studies on seven seeded grape cultivars under conditions of Qalubia governorate, Egypt. J. Appl. Sci., 17 (1) 285-306.

May, P. (2000): From bud to berry, with special reference to inflorescence and bud morphology in Vitis vinifera L. Aust. J. Grape Wine Res. 6:8298.

May, P., and A.J. Antcliff. (1963): The effect of shading on fruitfulness and yield in the Sultana. J. Hortic. Sci. 38:85-94.

Monastra, F. (1971): Pruning intensity in curtain trained vines. Rivista di Viticultura e di. Enologia 24 (6): 221-235. (Hort. Abst., 24:847).

Morrison, J. C. and lodi, M. (1990): The development of primary bud necrosis in Thompson Seedless and Flame Seedless grapevines. Vitis 29: 133144.

Naito, R., Yamamura, H. and Munesue, S. (1987): Studies on the necrosis in grapevine buds (III) the time of the occurrence of bud necrosis in 'Kyoho' and the relation between its occurrence and the amounts of nutritional elements in buds. Bull. Fac. Agric. Shimane Univ. 21:10-17.

Naito, R., Yamamura, H. and Yoshino, K. (1986): Effects of shoot vigor and foliar application of GA and SADH on the occurrence of bud necrosis in 'Kyoho' grape. J. Japan. Soc. Hort. Sci. 55: 130-137.

Perez, J. (1991): The influence of nitrogen fertilization on bud necrosis and bud fruitfulness of grapevines. Proc. Intl. Symp. on Nitrogen in Grapes and Wine, Seattle, Washington, USA, 18-19 June 1991. p 110-115.

Perez, J. and Kliewer, W. M. (1990): Effect of shading on bud necrosis and bud fruitfulness of 'Thompson Seedless' grapevines. Am. J. Enol. Vitic. 41: $168-175$.

Rawnsley, B., Wicks, T.W., Scott, E.S. and Stummer, B.S. (2002): Phomopsis and Diaporthe - distinction of the two fundi associated with Phomopsis cane and leaf spot. Australian and New Zealand Grapegrower and Winemaker, 464: 30-35.

Srinivasan, C., and M.G. Mullins. (1981): Physiology of flowering in the grapevine: A review. Am. J. Enol. Vitic. 32:47-63.

Snedecor, G. W. and Cochran. W.G. (1972): Statistical Methods . 6th ed, The lowa State Univ. Press . Ames. , lowa , U.S.A. , pp. 50

Swanepoel, J.J. and E. Archer (1988): The ontogeny and development of Vitis vinifera L. Cv. Chenin blanc inflorescence in relation to phenological stages. Vitis 27:133-141. 
Tourky, M.N., El-Shahat, S.S. and Rizk, M. H. (1995): Effect of Dormex on fruit set, quality and storage life of Thompson seedless grapes (Banati grapes) J. Agric. Sci., Mansoura Univ., 20(12): 5139-5151.

Williams, L.E. (2000): Bud development and fruitfulness of grapevines, In Raisin Production Manual. L.P. Christensen (Ed.), pp. 24-29. University of California Division of Agriculture and Natural Resources, Oakland.

Wolf, T. K. and Warren, M. K. (1995): Shoot growth rate and shoot density affect bud necrosis of 'Riesling' grapevines. J. Amer. Soc. Hort. Sci. 120:989996.

Ziv, M. M., Bernstein, Z. and Lavee, S. (1981): Necrosis in grapevine buds (Vitis vinifera cv. Queen of Vineyard). II. Effect of gibberellic acid $\left(\mathrm{GA}_{3}\right)$ application. Vitis 20: 105-114.

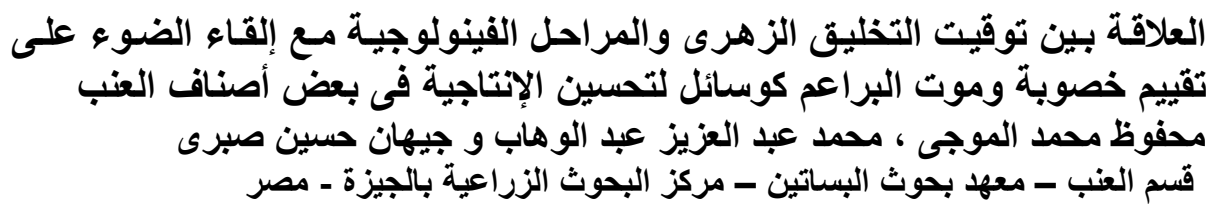

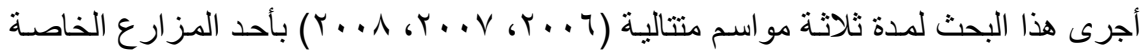

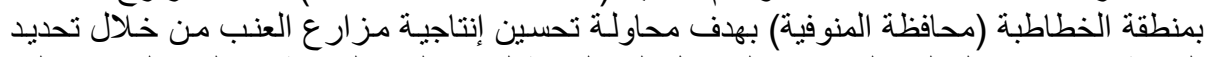

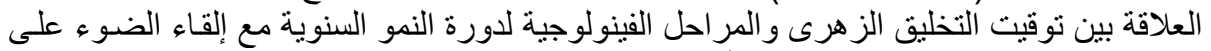

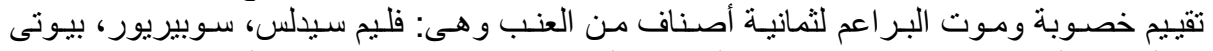

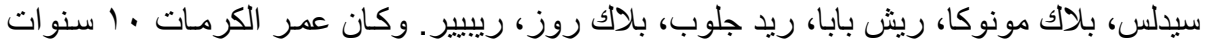

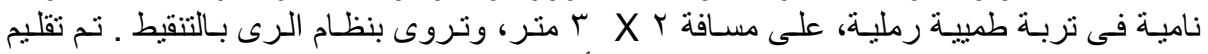
الكرمات تقليما قصبيا تحت نظام تدعيم التكاعيب الأسبانية.

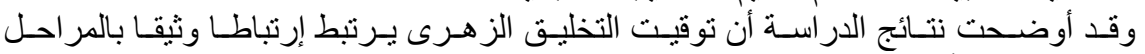

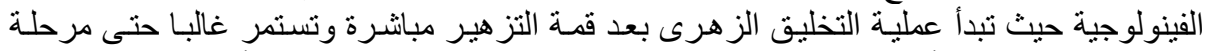

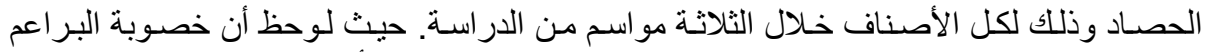

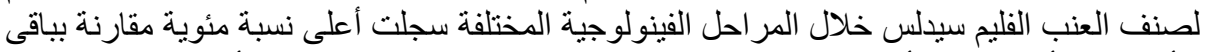

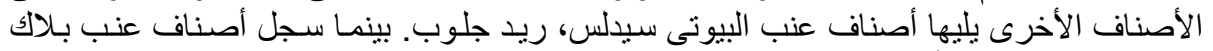
مونوكا ، السوبيريور أقل نسبة مئوية من خصوبة البر اعم خلال المر احل الفينولوجية للثيلاث مو اسم

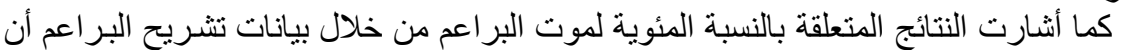
من الدراسة.

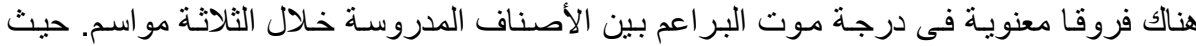

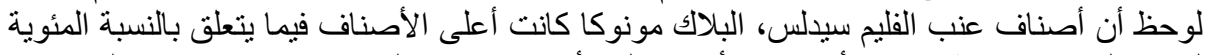

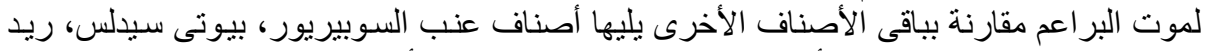

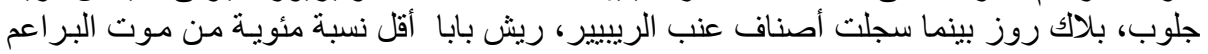

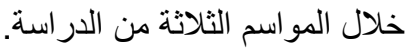

